Journal of Case Reports 2017;7(1):82-84

\title{
Perforated Duodenal Diverticulum
}

\author{
Vundavalli Sattibabu, Satish Dalal, Mahavir Singh Jangra, Tulit Chhabra \\ Department of General Surgery, Pt. B. D. Sharma Postgraduate Institute of Medical Sciences (P.G.I.M.S.), Rohtak-124001, Haryana, \\ India.
}

\section{Corresponding Author:}

Dr. Vundavalli Sattibabu

Email: vundavallisattibabu@gmail.com

This is an Open Access article distributed under the terms of the Creative Commons Attribution License (creativecommons.org/ licenses/by/3.0).

Received Accepted Published

\section{Introduction}

First reported by Chomel in 1710, the incidence of duodenal diverticula can be as high as $22 \%$ and complications can be estimated at $0.03 \%$ per year [1]. Duodenum is the second most common site for diverticula in the alimentary tract, second part of duodenum being the most frequent location [2]. Perforation is a rare, rarely reported and serious complication of duodenal diverticula, representing a diagnostic challenge and difficult surgical problem [3]. Here, we present a patient of perforated diverticulum in second part of the duodenum and its surgical management.

\section{Case Report}

A 70 year old, male patient presented to our emergency department with generalised pain abdomen, fever and abdominal distension. Examination showed normotensive patient with tachycardia of 110 beats per minute. Hematological and biochemical investigations showed hemoglobin: $13 \mathrm{gm} \%$; total leukocyte count: 15000 cells/ $\mu \mathrm{L}$ with $92 \%$ neutrophils in the differential count, and blood urea: $46 \mathrm{mg} / \mathrm{dL}$. Other biochemical investigations were within normal limits.

Abdominal X-ray showed no gas under diaphragm and ultrasonography showed thickened gall bladder wall with calculus of size $18 \mathrm{~mm}$ in its lumen.A provisional diagnosis of acute cholecystitis was made based on clinical presentation of the patient and patient was managed conservatively with intravenous antibiotics, analgesics and intravenous fluids with no clinical improvement. Abdominal CT scan next day showed retroperitoneal free air with surrounding mesenteric fat stranding suggestive of bowel perforation [Fig.1].

An emergency laparotomy was performed. After mobilisation of duodenum a perforated diverticulum was noted in the second part of duodenum [Fig.2] with surrounding phlegmon. We carried out diverticulectomy with double layer closure of the defect with feeding jejunostomy and nasogastric tube in situ. Patient improved well and nasogastric tube was removed on $4^{\text {th }}$ postoperative day. Feeding started through feeding jejunostomy 
and patient was discharged on $8^{\text {th }}$ postoperative day. On follow up, feeding jejunostomy was removed and patient started oral feed which he tolerated well.

\section{Discussion}

Duodenal diverticulum can be congenital or acquired, with the latter being the most common. Congenital diverticula contain all layers of the duodenal wall and acquired ones represent pulsion diverticula due to protrusion of mucosa, muscularis mucosa and submucosa through a wall weakness along with papillae and explaining why the area within $2.5 \mathrm{~cm}$ of the ampulla of Vater is the predilection site for such pathology $[1,4]$.

Duodenal diverticula are mostly asymptomatic, however complications such as bleeding, inflammation, compression of surrounding organs and perforation can develop in $5 \%$ of patients. Perforation represents the rarest but most serious complication, with mortality of upto $13 \%$ [5]. Perforated duodenal diverticulum poses a diagnostic challenge as there are no pathognomonic clinical features. The symptoms are mostly nonspecific and could mimic conditions such as peptic ulcer disease, acute cholecystitis and pancreatitis [6]. Majority of patients present with acute onset epigastric or right upper quadrant pain associated with nausea and vomiting. As in our case a provisional diagnosis of acute cholecystitis was made based on clinical scenario of the patient. The diagnosis is by exclusion and requires clinician to possess a high index of suspicion.

Conventional radiological examination will show no abnormality in half the patients with duodenal diverticular perforation. Abdominal CT is a valuable diagnostic modality due to its ability to detect small amount of extra-luminal air and delineate the retroperitoneal anatomy. It can even demonstrate the presence of a diverticulum in some cases. Typical radiological findings include thickened bowel wall, fat stranding and extra-luminal air or fluid [5,7]. In patients with

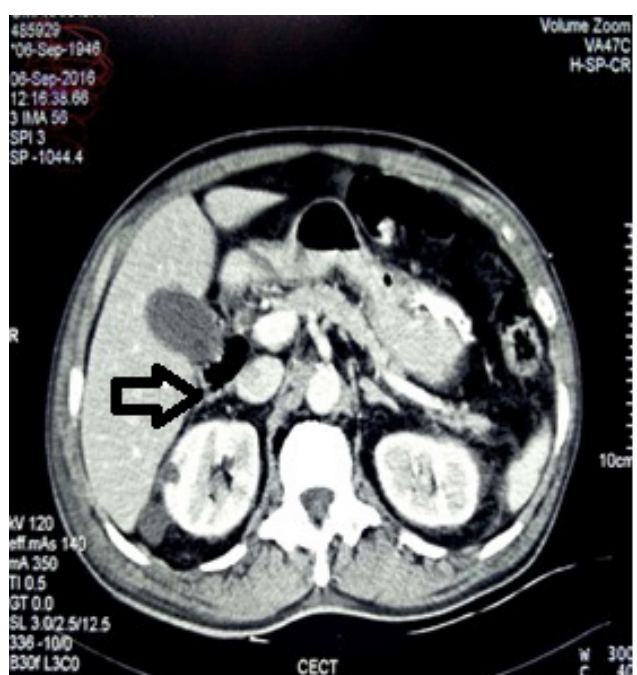

Fig.1: CT abdomen showing retroperitoneal air.

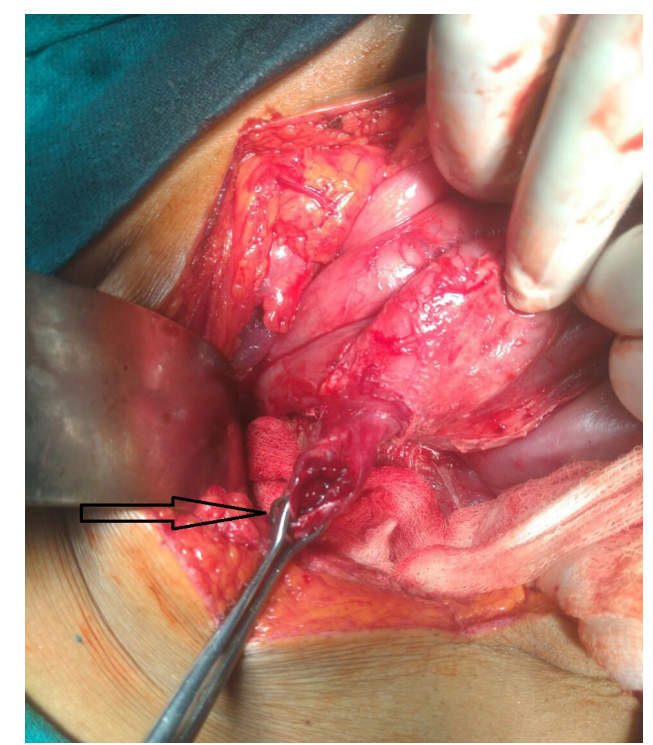

Fig.2: Intraoperative perforated duodenal diverticulum.

no evidence of impending sepsis, non-operative treatment for perforated diverticula is safe and a practical alternative to surgery. Treatment in such cases includes nasogastric suction, bowel rest, intravenous antibiotic therapy, parenteral nutrition, endoscopic cleaning of the infected pouch and combined endoscopic and percutaneous drainage of retroperitoneal abscess $[7,8]$. Close clinical observation is mandatory and surgical intervention is indicated if conservative management fails. 
Standard treatment forperforated diverticula is surgical intervention. Diverticulectomy with single or double layer closure is the most frequent reported alternative if inflammation permits [7]. As in our case diverticulectomy with double layer closure achieved good results. When substantial duodenal or retroperitoneal inflammation is present, more complex procedures like duodenal diversion, gastroenteric anastomosis, tube duodenostomy, segmental duodenal resection or even pylorus preserving Whipple might be required. Surgical morbidity includes duodenal leak or fistula, abscess, iatrogenic injury to the common bile duct, acute pancreatitis and persistent sepsis.

\section{Conclusion}

Perforation represents the rarest complication of duodenal diverticulum. Early diagnosis is challenging but CECT abdomen may give some clue for the diagnosis. Early surgical intervention is the treatment of choice but in selected patients non-operative management may be required.

Contributors: VS: Manuscript writing, case management; SD, MSJ: manuscript revision, case management; TC: photographs and critical review of manuscript for intellectual content. VS will act as guarantor. All authors approved the final version of manuscript.

Funding: None; Competing interests: None stated.

\section{References}

1. De Perrot T, Poletti PA, Becker CD, Platon A. The complicated duodenal diverticulum: retrospective analysis of 11 cases. Clin Imaging. 2012;36:287-294.

2. 2. Ming TY, Feng HK, Cherng YJ, Chuan CD, Pai LT, Chi LY. Clinical challenge: diverticulitis of third and fourth portion of the duodenum with perforation. Rev Esp Enferm Dig. 2012;104:156-159.

3. Rossetti A, Christian BN, Pascal B, Stephane D, Philippe M. Perforated duodenal diverticulum, a rare complication of a common pathology: a seven-patient case series. World J Gastrointest Surg. 2013;5:47-50.

4. Thorson CM, Paz Ruiz PS, Roeder RA, Sleeman D, Casillas VJ. The perforated duodenal diverticulum. Arch Surg. 2012;147:81-88.

5. Schnueriger B, Vorburger S, Banz V, Schoepfer AM, Candinas D. Diagnosis and management of the symptomatic duodenal diverticulum. A case series and a short review of the literature. J Gastrointest Surg. 2008; 12:1571-1576.

6. Ames J, Federle M, Pealer K. Perforated duodenal diverticulum: Clinical and imaging findings in eight patients. Abdom Imaging. 2009;34:135-139.

7. Martinez-Cecilia D, Arjona-Sanchez A, Gomez-Alvarez $\mathrm{M}$, et al. Conservative management of perforated duodenal diverticulum: A case report and review of the literature. World J Gastroenterol. 2008;14:1949-1951.

8. Coulier B. Duodenal diverticulitis. JBR-BTR. 2008;91:271. 